\title{
Detection of circulating tumor cells with CK20 RT-PCR is an independent negative prognostic marker in colon cancer patients - a prospective study
}

Sebastian Hinz ${ }^{1 *}$, Alexander Hendricks' ${ }^{1}$, Amke Wittig ${ }^{2}$, Clemens Schafmayer ${ }^{1}$, Jürgen Tepel ${ }^{3}$, Holger Kalthoff ${ }^{2}$, Thomas Becker ${ }^{1}$ and Christian Röder ${ }^{2}$

\begin{abstract}
Background: Detection of circulating (CTC) or disseminated tumor cells (DTC) has been associated with negative prognosis and outcome in patients with colorectal cancer, though testing for these cells is not yet part of clinical routine. There are several different methodological approaches to detect tumor cells but standardized detection assays are not implemented so far.
\end{abstract}

Methods: In this prospective monocentric study 299 patients with colon cancer were included. CTC and DTC were detected using CK20 RT-PCR as well as immunocytochemistry staining with anti-pan-keratin and anti-EpCAM antibodies. The primary endpoints were: Evaluation of CTC and DTC at the time of surgery and correlation with main tumor characteristics and overall (OS) and disease free survival (DFS).

Results: Patients with detectable CTC had a 5-year OS rate of 68\% compared to a 5-year OS rate of $85 \%$ in patients without detectable CTC in the blood $(p=0.002)$. Detection of DTC in the bone marrow with CK20 RT-PCR was not associated with a worse OS or DFS. Detection of pan-cytokeratin positive DTC in the bone marrow correlated with a significantly reduced 5 -year OS rate $(p=0.048)$, but detection of DTC in the bone marrow with the anti-EpCAM antibody did not significantly influence the 5 -year OS rate $(p=0.958)$. By multivariate analyses only detection of CTC with CK20 RT-PCR in the blood was revealed to be an independent predictor of worse OS (HR1.94; 95\% CI 1.0-3.7; $p=0.04)$ and DFS (HR 1.94; 95\% Cl 1.1-3.7; $p=0.044)$.

Conclusions: Detection of CTC with CK20 RT-PCR is a highly specific and independent prognostic marker in colon cancer patients. Detection of DTC in the bone marrow with CK20 RT-PCR or immunohistochemistry with anti-EpCAM antibody is not associated with a negative prognostic influence.

Keywords: Circulating tumor cells, CTC, DTC, CK20 RT-PCR, CK20, Colon carcinoma, EpCAM

\section{Background}

Even though many efforts had been made in the past with regarding prevention, early diagnosis and also optimizing therapeutic strategies adenocarcinoma of the colon still poses a considerable clinical problem. With mortality being nearly half as high as the relatively high

\footnotetext{
* Correspondence: sebastian.hinz@uksh.de

${ }^{1}$ Department of General and Thoracic Surgery, University Hospital

Schleswig-Holstein, Campus Kiel, Arnold-Heller Str. 7, 24105 Kiel, Germany

Full list of author information is available at the end of the article
}

incidence of 51.7, it significantly contributes to cancerrelated mortality in industrialized countries [1].

Long-term survival after putative complete tumor resection is mainly threatened by distant metastases, derived from circulating tumor cells. Hereby, tumor cells that can be detected in the peripheral blood are termed circulating tumor cells (CTC), whereas tumor cells found in the bone marrow are termed disseminated tumor cells (DTC). In particular the mechanisms, how cancer cells acquire the ability to seed out metastases in distant organs still pose one of the principal query in the 
treatment of advanced cancer. According to the "revisited" hypothesis of "seed and soil", it does not only depend on the cell itself, but also on local environmental factors, whether circulating tumor cells can develop and grow out into liver and lung metastases [2]. To improve survival, systemic treatment is recommended for patients with proven lymph node metastases. However, conventional pathological staging criteria do lead to an underestimation of the actual tumor stage in nearly $25 \%$ of the patients as has been shown by sentinel lymph node mapping [3]. The dissemination of sole tumor cells, which may stand for the starting point of tumor recurrence, cannot be detected by conventional staging methods so far. However, initial studies demonstrated that immuno-cytological and molecular-biological techniques are able to identify disseminated tumor cells in the bone marrow, blood, peritoneal cavity and lymph nodes of cancer patients [4,5]. Using the Polymerase Chain Reaction (PCR), increased sensitivity and more objective results could be reached [6]. It has been demonstrated in several studies that molecular biomarkers or high-risk gene signatures help to identify patients who are candidates of a worse clinical course [7], but with the exception of patients with mutated KRAS in metastatic colorectal cancer, predictive factors are still lacking [8].

Our analytical system assessed the ectopic expression by nested RT-PCR in blood and bone marrow of cytokeratin (CK) 20-mRNA, coding for an intermediate filament protein of epithelial cells. CK20 is expressed in gastrointestinal epithelial cells among others, as well as in tumors derived from these cells. The mRNA and protein can be detected in $97 \%$ of colon tumors [9]. Previously, we demonstrated that our CK20 nested RTPCR assay is highly sensitive and specific [10], and also shows tumor stage-related detection rates in clinical samples [11].

The majority of studies analyzing the role of CTC have been including colon and rectal cancer patients in the same cohort summed as colorectal cancer patients as a whole. We have previously shown that in rectal cancer patients CTC detection by CK20 expression is not a prognostic marker, but a marker for response to neoadjuvant chemoradiation [12]. This finding even more stresses the biological differences and distinct modes of metastasis of colon and rectal cancer, which is underestimated in most clinical trials. Hence, we included only patients with colon cancer in this prospective study.

The presence of disseminated tumor cells can serve as an indicator for systemic disease at the time of primary tumor resection. Initial studies based on the immunocytochemical detection of cytokeratin-positive cells in blood or peritoneal lavage confirmed for the prognostic relevance of such minimal residual disease in otherwise
R0-resected patients [13]. Several studies in patients with colorectal carcinoma employing either immunocytochemical methods or CK20 RT-PCR supported such findings in multivariate analyses in small cohorts of 53 and 90 patients, respectively $[14,15]$. The prognostic significance of minimal residual disease in a larger multicenter trial of clinically relevant size remains to be shown.

During the last years detection of DTC and CTC with anti-EpCAM based detection systems has gained broad popularity. The CellSearch System (Veridex, Raritan, USA) has been approved for the detection of CTC in metastatic colorectal cancer [16] by the Food and Drug Administration (FDA) in the USA. Though a clear disadvantage of anti-EpCAM based detection systems is: A change in the expression profile during metastatic spread of tumor cells, which has already been reported as epithelial-mesenchymal transition (EMT) [17], may result in lower detection rates of CTC.

We investigated bone marrow and peripheral blood of colon carcinoma patients by CK20-specific nested RTPCR after isolation of the mononuclear cell (PBMC) fraction and preparation of total RNA. In addition, DTC in bone marrow blood were analyzed in a subset of patients using immunocytochemistry with anti-pancytokeratin or anti-EpCAM antibodies. All patients underwent complete (R0) tumor resection and were subjected to a detailed clinical follow up. The primary endpoints of this study were: Evaluation of CTC and DTC at the time of surgery and correlation with main tumor characteristics and overall (OS) and disease free survival (DFS) in a large cohort of colon cancer patients with a reasonable long follow-up.

\section{Methods \\ Patients}

A total of 299 patients with colon cancer that underwent surgery at the Department of General and Thoracic Surgery, University Hospital Kiel, were sequentially included during a 7 year study period in this investigation. The study was approved by the local ethics committee of the Christian-Albrechts University, Kiel (A110/99) and all patients gave written informed consent prior to inclusion in the study. Patients with rectal cancer were not included. A total of 227 bone marrow and 299 venous blood samples were collected directly before skin incision and transferred to the laboratory for extraction of the mononuclear cells within $2 \mathrm{~h}$. In all patients with stage IV disease (only liver metastases) the patients underwent synchronous liver resection. Only patients who underwent complete tumor (R0)-resection were included. Patients that underwent surgery for recurrent disease or had other malignancies were excluded from this study. Classification of the pathological tumor-stage and grade was performed at the Department of 
Pathology, University Hospital Schleswig-Holstein, Campus Kiel, according to the TNM-classification. The patient's overall survival was one of the main endpoint result of our study. This was determined as the number of months between the date of surgery and the date of death or the date of the last follow up. Clinical follow-up was performed in cooperation with general practitioners and with the Cancer Registry of the Federal State of Schleswig-Holstein (Bad Segeberg, Germany). All individual data were obtained from the clinical research data base of the oncological biobank BMB-CCC of the Comprehensive Cancer Center Kiel and data were verified by re-examination of original patient records and of the PCR and immunocytochemistry results. Only patients with complete clinical data were considered for further analysis.

Patients with UICC-stage-III colon carcinoma were recommended to receive adjuvant chemotherapy and the vast majority did so. Patients developing recurrent disease during follow-up received either surgical treatment or palliative chemotherapy.

\section{Control group}

The control collective (total $n=76$ individuals) consisted of 38 healthy volunteers from whom peripheral venous blood samples $(n=38)$ were obtained. The volunteers were randomly recruited and not age/sex matched. Furthermore, 32 bone marrow samples and 30 venous blood samples were collected from a second group of $38 \mathrm{pa}-$ tients ( 6 bone marrow donors, 8 leukemia patients, and 24 patients with non-malignant diseases (liver cysts, liver adenoma, sigmoid diverticulitis, FAP, pancreatitis, hernias, ulcera ventriculi, primary sclerosing cholangitis). Part of this collective was already utilized and described in a previous report [11]. Informed written consent for participation in the study was obtained from all individuals of the control cohort and investigation of the samples was covered by the same approval of the local ethics committee as above for cancer patients.

\section{Sample collection, isolation of RNA and RT-PCR}

Prior to surgery, $10 \mathrm{ml}$ bone marrow blood was aspirated from the spina iliaca anterior under general anesthesia subsequent to a small cutaneous incision. Venous blood $(20 \mathrm{ml})$ was taken in parallel from a central venous line. Lithium heparin was used as anticoagulant. Fractions of mononuclear cells from blood or bone marrow were isolated by centrifugation through a Ficoll-Hypaque density cushion (GE Healthcare, Freiburg, Germany) according to the manufacturer's recommendation. After washing in PBS, cells were counted, pelleted again, and subsequently centrifuged onto microscopic slides (cytospins) or lysed for RNA preparation with RNAPure reagent (PQLab, Erlangen, Germany) and further processed according to the manufacturer's protocol. Total RNA was isolated and checked for integrity using a Bioanalyzer 2100 instrument (Agilent Technologies, Böblingen, Germany). CDNA synthesis and nested CK20 RT-PCR analysis was exactly performed as previously described in detail [11]. Every sample was assessed in triplicate. If at least one positive PCR test out of three was obtained, the sample was rated as CK20-positive. All assessments of PCR results were performed blinded, without knowledge of the clinical data.

\section{Immunocytochemistry}

Mononuclear cell fractions from bone marrow blood were centrifuged as cytospins (Cytospin Centrifuge, Hettich, Germany) using $5 \times 10^{5}$ cells per spot and slide. Slides were air-dried and stored dry and tightly sealed at $-20{ }^{\circ} \mathrm{C}$ until further use. Cells were stained after $5 \mathrm{mi}-$ nutes aceton fixation, either with the primary pancytokeratin antibody A45-B/B3 detecting CK8, CK18 and CK19 (AS Diagnostik, Germany) or anti-EpCAM antibody BER-EP4 (Dako, Hamburg) using the Dako REAL detection system (Dako, Hamburg, Germany). Cytospins were analysed with an ACIS (automated cellular imaging system; Chromavision medical systems, St. Juan Capistrano, CA, USA) followed by manual microscopy by an independent scientist. Only positive cells with distinct morphological signs of a tumor cell were counted as positive cells [18]. Detection of at least one positive tumor cell regarded this patient as a positive case.

\section{Statistical analysis}

Univariate Kaplan-Meier survival analysis was performed to compute the cumulative overall survival (OS) and disease free survial (DFS) rate in dependence on the CK20RT-PCR status in blood and/or bone marrow and the positivity in immunocytochemistry, respectively. The detection rate of CTC and DTC and correlation with clinicopathologic parameters were analyzed with the $x^{2}$ test after crosstab analysis. Differences in the survival curves of the subgroups were assessed by the log-rank test. The Cox proportional-hazards model was used for multivariate analysis. Independence of categorical variables was tested by Pearson's $X^{2}$ test after crosstab analysis. All reported P-values are two-sided and differences were judged significant if $\mathrm{P}$ was 0.05 or less. Calculations and tests were performed with SPSS 23.0 (SPSS Inc., Chicago, IL).

\section{Results}

\section{Clinical characteristics}

Our study population consisted of 299 patients with colon cancer. 108 patients (36.3\%) underwent a right-sided hemicolectomy and 36 patients (12\%) underwent a leftsided hemicolectomy. In 18 patients $(6 \%)$ we performed a 
transverse-colon resection and in 122 patients (40.8\%) a sigmoid resection was necessary. Fifteen patients (5\%) were treated with a subtotal colectomy. All patients underwent open surgery. The mean age at the time of surgery was 67.4 years (range 29-92 years). The clinical and histological parameters are summarized in Table 1.

\section{Correlation of clinicopathologic characteristics and survival}

The median follow-up was 55 months (range 4168 months) and the 5-year overall survival (OS) rate for all patients included in the study was $78 \%$. As expected, we found a strong correlation between tumor stage and OS. Furthermore, high pT-category and positive lymph node status predicted a highly significant worse 5-year OS and DFS rate $(p<0.001)$ (Table 1$)$.

\section{Association of CTC and DTC detection with CK20 RT-PCR and clinicopathologic characteristics}

The overall detection rate for circulating tumor cells in the blood (CTC) as determined by CK20 RT-PCR was $37.4 \%$ (Table 1). Higher tumor stage and pT category correlated with a higher detection rate of CTC by CK20 RT-PCR ( $p=0.017$ and $p=0.019$, respectively), whereas the status of lymph node metastasis $(\mathrm{pN})$ did not correlate with the detection rate of CTC or DTC (Table 2). A large number of patients who were treated for

Table 1 Patients' clinical and pathological characteristics and univariate analysis of factors influencing the 5-year overall survival (OS) and disease free survival (DFS) rate

\begin{tabular}{|c|c|c|c|c|c|c|c|}
\hline Characteristics & Category & $n$ & $\%$ & $5 y-O S(\%)$ & $P$ & $5 y$-DFS (\%) & $P$ \\
\hline CK20 blood & positive & 112 & 37.4 & 68 & 0.002 & 78 & 0.021 \\
\hline$(n=299)$ & negative & 187 & 62.6 & 85 & & 89 & \\
\hline CK20 bone marrow & positive & 81 & 35.7 & 71 & 0.09 & 85 & 0.419 \\
\hline$(n=227)$ & negative & 146 & 63.3 & 79 & & 86 & \\
\hline pan-cytokeratin & positive & 30 & 22.4 & 59 & 0.048 & 61 & 0.041 \\
\hline$(n=134)$ & negative & 104 & 77.6 & 76 & & 80 & \\
\hline EpCAM & positive & 12 & 19.7 & 55 & 0.958 & 44 & 0.548 \\
\hline$(n=61)$ & negative & 49 & 80.3 & 64 & & 72 & \\
\hline \multirow[t]{2}{*}{ Sex } & male & 168 & 56.2 & 79 & 0.70 & 84 & 0.563 \\
\hline & female & 131 & 43.8 & 77 & & 87 & \\
\hline \multirow[t]{2}{*}{ Age [years] } & $<70$ & 160 & 53.5 & 82 & 0.045 & 88 & 0.332 \\
\hline & $>70$ & 139 & 46.5 & 74 & & 83 & \\
\hline \multirow[t]{4}{*}{ UICC stage } & 1 & 87 & 29.1 & 98 & $<0.001$ & 99 & $<0.001$ \\
\hline & $\|$ & 94 & 31.4 & 89 & & 90 & \\
\hline & III & 80 & 26.8 & 71 & & 77 & \\
\hline & IV & 38 & 12.7 & 24 & & 48 & \\
\hline \multirow[t]{4}{*}{ pT } & $\mathrm{T} 1$ & 42 & 14.0 & 98 & $<0.001$ & 98 & 0.005 \\
\hline & $\mathrm{T} 2$ & 70 & 23.4 & 89 & & 94 & \\
\hline & $\mathrm{T} 3$ & 159 & 53.2 & 73 & & 80 & \\
\hline & $\mathrm{T} 4$ & 28 & 9.4 & 47 & & 75 & \\
\hline \multirow[t]{3}{*}{$\mathrm{pN}$} & NO & 190 & 63.6 & 91 & $<0.001$ & 93 & $<0.001$ \\
\hline & $\mathrm{N} 1$ & 65 & 21.7 & 64 & & 76 & \\
\hline & N2 & 44 & 14.7 & 46 & & 64 & \\
\hline \multirow[t]{3}{*}{ Grading } & G1 & 21 & 7.0 & 95 & 0.054 & 76 & 0.704 \\
\hline & G2 & 236 & 78.9 & 79 & & 85 & \\
\hline & G3 & 42 & 14.1 & 65 & & 91 & \\
\hline \multirow[t]{5}{*}{ Operation } & right hemicolectomy & 108 & 36.3 & & & & \\
\hline & left hemicolectomy & 36 & 12.0 & & & & \\
\hline & transverse colon resection & 18 & 6.0 & & & & \\
\hline & sigmoid colon resection & 122 & 40.8 & & & & \\
\hline & subtotal colectomy & 15 & 5.0 & & & & \\
\hline
\end{tabular}


Table 2 Number of patients with CK20 positive tumor cells and association with patients' characteristics

\begin{tabular}{|c|c|c|c|c|c|c|c|}
\hline Characteristics & category & $\begin{array}{l}\text { CK20+ } \\
\text { BL }\end{array}$ & Detection rate (\%) & $P$ & CK20+BM & Detection rate (\%) & $P$ \\
\hline All & & 112 & 37.4 & - & 81 & 35.7 & - \\
\hline \multirow[t]{2}{*}{ Sex } & male & 60 & 35.7 & 0.50 & 42 & 31.3 & 0.101 \\
\hline & female & 52 & 39.7 & & 39 & 41.9 & \\
\hline \multirow[t]{2}{*}{ Age [years] } & $<70$ & 62 & 38.7 & 0.636 & 38 & 32.7 & 0.216 \\
\hline & $>70$ & 50 & 35.9 & & 43 & 39.8 & \\
\hline \multirow[t]{4}{*}{ UICC stage } & 1 & 28 & 32.2 & 0.017 & 20 & 31.7 & 0.633 \\
\hline & $\|$ & 32 & 34.0 & & 28 & 37.3 & \\
\hline & III & 29 & 36.2 & & 20 & 33.3 & \\
\hline & IV & 23 & 60.5 & & 13 & 44.8 & \\
\hline \multirow[t]{4}{*}{ pT } & $\mathrm{T} 1$ & 9 & 21.4 & 0.019 & 7 & 25.9 & 0.633 \\
\hline & $\mathrm{T} 2$ & 29 & 41.4 & & 21 & 38.8 & \\
\hline & T3 & 58 & 36.5 & & 44 & 35.7 & \\
\hline & $\mathrm{T} 4$ & 16 & 57.1 & & 9 & 39.1 & \\
\hline \multirow[t]{3}{*}{$\mathrm{pN}$} & No & 66 & 34.7 & 0.134 & 51 & 34.9 & 0.646 \\
\hline & N1 & 24 & 36.9 & & 20 & 40.8 & \\
\hline & N2 & 22 & 50.0 & & 10 & 31.2 & \\
\hline \multirow[t]{3}{*}{ Grading } & G1 & 7 & 35.0 & 0.280 & 5 & 33.3 & 0.252 \\
\hline & G2 & 84 & 35.6 & & 60 & 33.5 & \\
\hline & G3 & 21 & 48.8 & & 16 & 48.4 & \\
\hline \multirow[t]{2}{*}{ Liver Metastases } & MO & 89 & 35.1 & 0.002 & 68 & 34.3 & 0.271 \\
\hline & M1 & 23 & 62.1 & & 13 & 44.8 & \\
\hline
\end{tabular}

BL blood, BM bone marrow

The data in bold are regarded statistically significant $(p<0.05)$

synchronous liver metastases combined with colon resection (pM1) were significantly positive for CTC in the blood $(p=0.002)$ (Table 2). Interestingly, we did not find any correlation between detection of disseminated tumor cells (DTC) by CK20 RT-PCR in the bone marrow and any clinicopathologic parameters analyzed (Table 2, right columns) although the general detection rate of DTC (35.7\%) was nearly similar to the detection rate in the blood.

\section{Correlation analysis of survival and CTC and DTC detection by CK20-RT-PCR}

Detection of CTC by CK20 RT-PCR in the blood of 299 patients was correlated with a significantly worse 5 -year OS and DFS rate. Patients with detection of CTC had a 5year OS rate of $68 \%$ compared to a 5 -year OS rate of $85 \%$ in patients without detectable CTC in the blood $(p=0.002)$ (Fig. 1a, c). By contrast, analysis of bone marrow blood samples of 227 patients did not reveal a significant correlation between the CK20 expression status and the 5-year OS $(p=0.098)$ or DFS rate $(p=0.419)$ (Fig. 1b, d). During the follow-up period, $38(12.7 \%)$ patients developed a recurrent disease. Patients with detectable CTC with CK20 RT-PCR had a significantly higher risk to develop a recurrent disease (20/38 patients, $52.6 \%)$ compared to the group without CTC $(92 / 216,35.2 \%)$ ( $p=0.042, \chi^{2}$ test after crosstab analysis). To further evaluate, if detection of CTC by CK20 RT-PCR is an applicable strategy to stratify CK20-positive high risk patients with UICC stage II disease against UICC Stage III patients without detectable CTC, we compared these two groups regarding detection rate of CK20 and the 5-year-OS or DFS rate. We did not find any significant differences with respect to detection rate or survival (data not shown).

\section{Control group}

To determine the specificity of the CK20 RT-PCR we analyzed a control group of 76 individuals. This group consisted of blood samples from 38 healthy volunteers. In none of these healthy volunteers the CK20 RT-PCR was positive. Furthermore, we analyzed 32 bone marrow and 30 blood samples from a control group of 38 patients with different diseases (see Methods section). In these patients two bone marrow samples were tested positive for CK20. One patient had a familial adenomatosis polyposis (FAP) and underwent colectomy without detection of a colon cancer. The other patient suffered from a giant adenoma of the liver with 


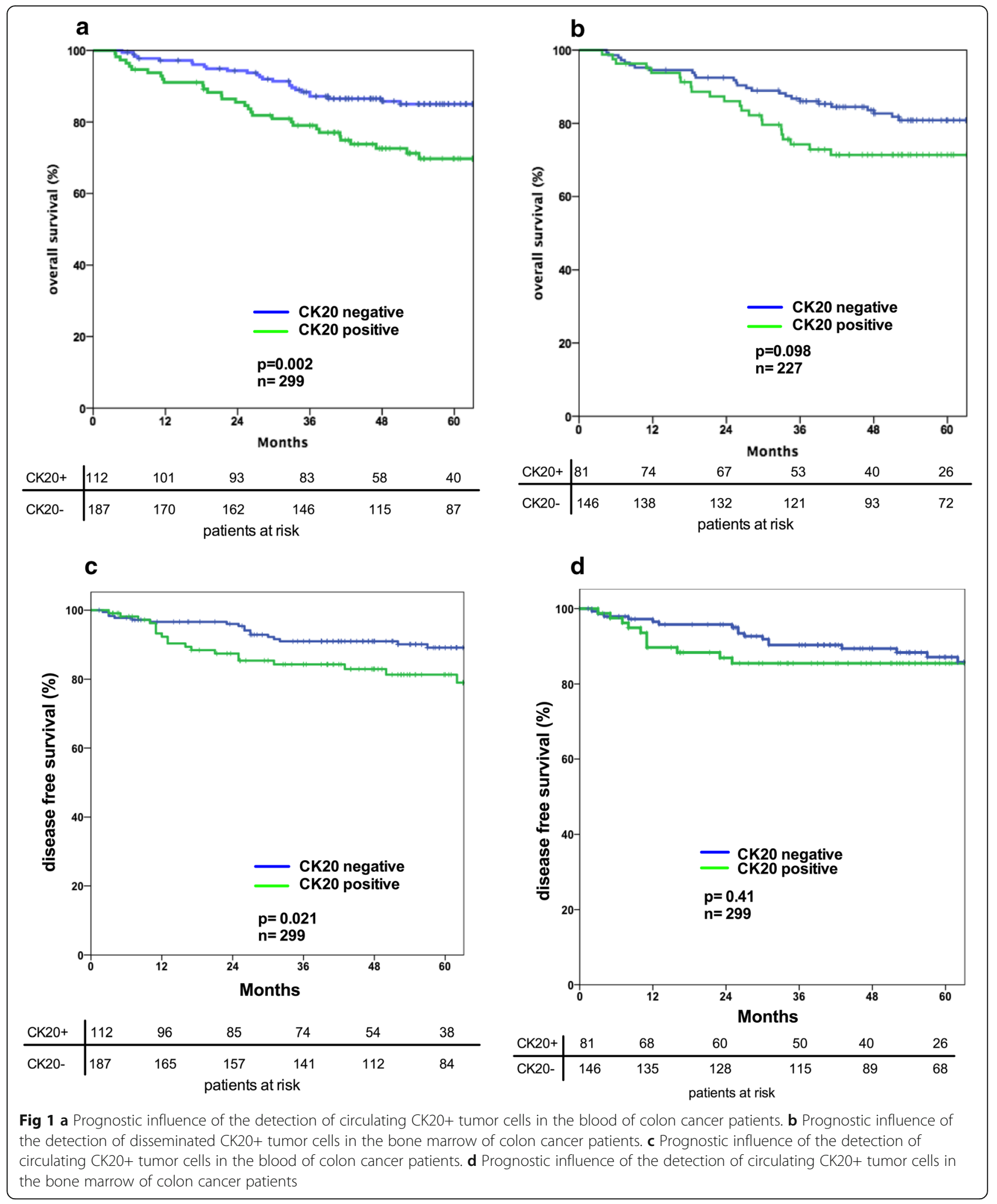

a tumor mass of about $1.5 \mathrm{~kg}$ which was resected. This patient was also tested positive for CK20 in the blood. A second patient suffering from a chronic pancreatitis and undergoing pancreatic head resection was also tested positive for CK20 in the blood. Overall, none of the healthy controls were tested positive for CK20. The positive cases were already reported earlier by our group [11]. 
Detection of DTC in the bone marrow by immunocytochemistry and correlation with clinicopathologic characteristics

As we could not observe any correlation of DTC detection in the bone marrow with CK20 RT-PCR and clinical parameters (Table 2) we additionally applied immunocytochemistry with two different antibodies to detect DTC in the bone marrow on the level of protein expression as an established alternative approach. The detection rate of DTC by immunocytochemistry was $22.3 \%$ with the pan-cytokeratin antibody A45-B/B 3 and 19.7\% with anti-EpCAM antibody BER-EP4, respectively. The overall detection rate of DTC by immunocytochemistry was remarkably lower compared to CK20 RT-PCR. We could not demonstrate a correlation between the detection of DTC with pan-cytokeratin or anti-EpCAM antibody and any of the tested clinicopathologic parameters (Table 3).

\section{Correlation of survival and DTC detection by immunocytochemistry}

Detection of pan-cytokeratin positive DTC in the bone marrow was significantly correlated with a reduced 5year OS rate of $59 \%$ compared to $76 \%$ in patients without cytokeratin positivity in the bone marrow $(p=0.048)$ (Fig. 2a). In line with this finding also the DFS was significantly reduced in patients with CK20-positive DTC in the bone marrow $(p=0.041)$ (Fig. 2c). Detection of DTC in the bone marrow with the anti-EpCAM antibody BER-EP4 did not significantly influence the 5year OS $(p=0.958)$ or DFS rate $(p=0.548)$, respectively (Fig. 2b, d). Some exemplary immunohistochemistry stainings of pan-cytokeratin or anti-EpCAM positive DTC are shown in Additional file 1: Figure S1.

To further evaluate the relevance of DTC detection in the bone marrow, we combined detection of DTC in the bone marrow with either CK20 RT-PCR or immunocytochemistry (pan-cytokeratin or anti-EpCAM). With the combinational approach of these two different detection methods of DTC in the bone marrow we were able to increase the detection rate to $49.6 \%$ (62 of 125 patients positive with either technology/ antibody). The OS of the patients with detectable DTC in the bone marrow with either technology was not different from patients without DTC $(p=0.098)$.

\section{Multivariate cox regression analysis for independent factors influencing survival}

All variables that showed a significant correlation in the univariate analysis were included in a Cox regression model. By multivariate analyses, detection of CTC by CK20-RT-PCR in the blood was revealed as an independent predictor of worse OS (HR1.94; 95\% CI 1.0-3.7; $p=0.04$ ). Higher UICC stage (HR 6.4; 95\% CI 1.6-26.3; $p=0.01$ ) and higher T stage (HR 3.3; 95\% CI 1.3-8.4; $p=0.015)$ were also independent markers of worse OS. These markers were also independent predictors of an inferior DFS (Table 4).

Table 3 Number of patients with pan-cytokeratin or EpCAM positive tumor cells in the bone marrow detected with immunohistochemistry and association with patients' characteristics (crosstabs, chi-square test, two sided)

\begin{tabular}{|c|c|c|c|c|c|c|c|}
\hline Characteristics & Category & pan-cytokeratin & Detection rate (\%) & $P$ & EpCAM & Detection rate (\%) & $P$ \\
\hline All & & $30(134)$ & 22.3 & - & $12(61)$ & 19.7 & - \\
\hline \multirow[t]{4}{*}{ UICC stage } & । & $6(30)$ & 20.0 & 0.335 & $2(8)$ & 25.0 & 0.587 \\
\hline & $\|$ & $7(40)$ & 17.5 & & $2(14)$ & 14.2 & \\
\hline & III & $8(39)$ & 20.5 & & $3(22)$ & 13.6 & \\
\hline & IV & $9(25)$ & 36.0 & & $5(17)$ & 29.4 & \\
\hline \multirow[t]{4}{*}{ pT } & $\mathrm{T} 1$ & $4(16)$ & 25.0 & 0.861 & $2(5)$ & 40.0 & 0.575 \\
\hline & $\mathrm{T} 2$ & $4(25)$ & 16.0 & & $1(10)$ & 10.0 & \\
\hline & T3 & $17(5)$ & 29.4 & & 7 (34) & 20.6 & \\
\hline & T4 & $5(22)$ & 22.7 & & $2(12)$ & 16.4 & \\
\hline \multirow[t]{3}{*}{$\mathrm{pN}$} & No & $14(75)$ & 18.6 & 0.324 & $5(24)$ & 20.8 & 0.253 \\
\hline & $\mathrm{N} 1$ & $8(35)$ & 22.8 & & $2(21)$ & 9.5 & \\
\hline & N2 & $8(24)$ & 33.3 & & $5(16)$ & 31.2 & \\
\hline \multirow[t]{3}{*}{ Grading } & G1 & $1(9)$ & 11.1 & 0.702 & $0(3)$ & 0 & 0.108 \\
\hline & G2 & $23(99)$ & 23.23 & & $12(47)$ & 25.5 & \\
\hline & G3 & $6(26)$ & 23.1 & & $0(11)$ & 0 & \\
\hline Liver & MO & $21(104)$ & 20.1 & 0.07 & 7 (44) & 15.9 & 0.287 \\
\hline Metastases & M1 & $9(30)$ & 30 & & $5(17)$ & 29.4 & \\
\hline
\end{tabular}




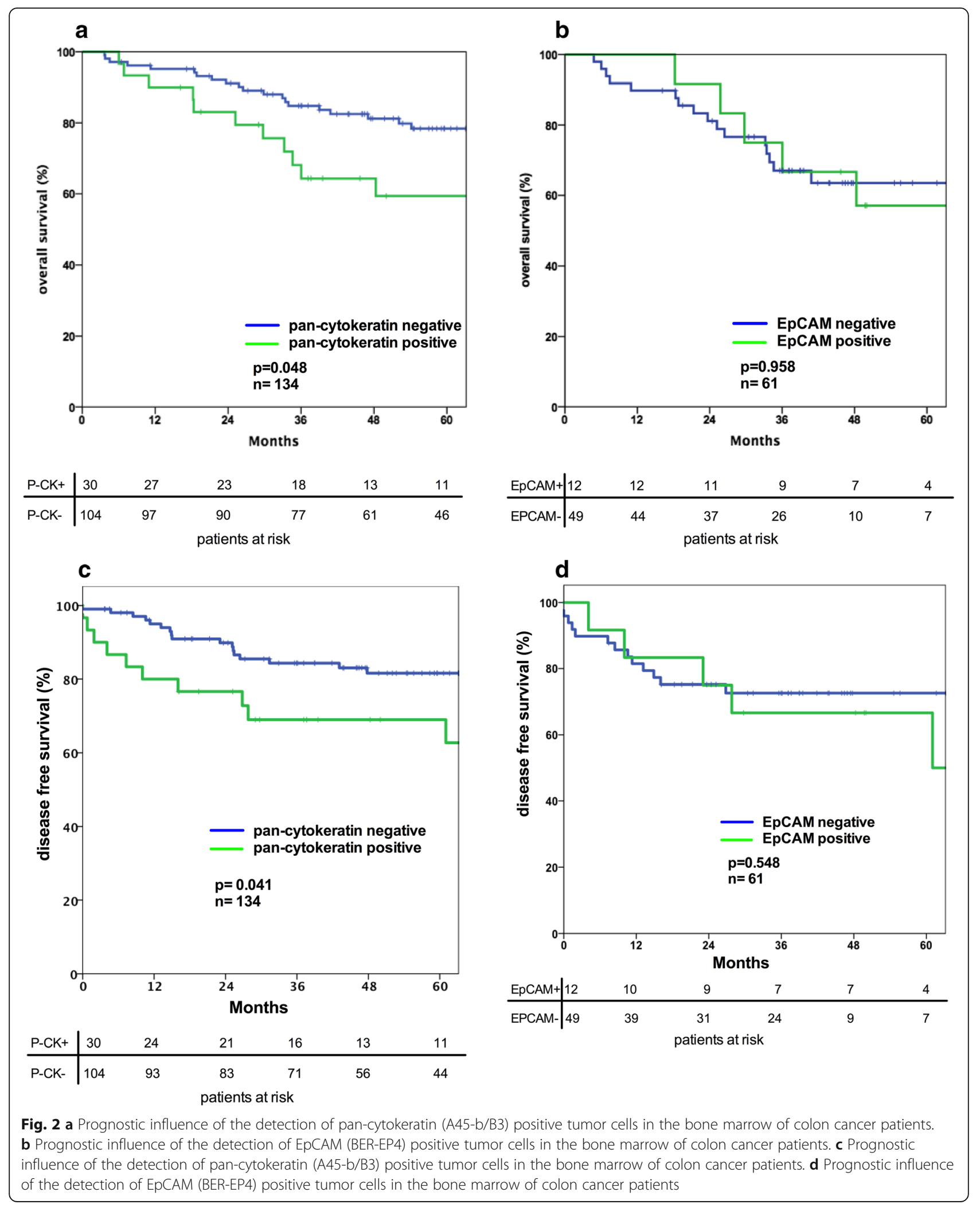


Table 4 Multivariate Cox regression analysis of independent factors influencing overall and disease free survival

\begin{tabular}{cllll}
\hline Factor & Category & Hazard ratio & $95 \% \mathrm{Cl}$ & $P$ value \\
\hline $\begin{array}{c}\text { Overall survival } \\
\text { CK20 blood }\end{array}$ & positive vs. negative & 1.94 & $1.0-3.7$ & $\mathbf{0 . 0 4 2}$ \\
Age [years] & $<70$ vs. $>70$ & 2.7 & $1.4-5.4$ & $\mathbf{0 . 0 0 4}$ \\
pN stage & pN0 vs. pN1/2 & 0.7 & $0.2-2.7$ & 0.62 \\
pT stage & pT1/2 vs. pT3/4 & 3.3 & $1.3-8.4$ & $\mathbf{0 . 0 1 5}$ \\
UICC stage & I + II vs. III + IV & 6.4 & $1.6-26.3$ & $\mathbf{0 . 0 1}$ \\
Disease free survival & & & \\
CK20 blood & positive vs. negative & 1.94 & $1.1-3.7$ & $\mathbf{0 . 0 4 4}$ \\
pN stage & pN0 vs. pN1/2 & 1.39 & $0.3-5.8$ & 0.65 \\
pT stage & pT1/2 vs. pT3/4 & 2.88 & $1.1-7.5$ & $\mathbf{0 . 0 3}$ \\
UICC stage & I+ II vs. III + IV & 4.9 & $1.0-23.7$ & $\mathbf{0 . 0 4 5}$
\end{tabular}

Abbreviation: $\mathrm{Cl}$ confidence interval

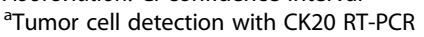

The data in bold are regarded statistically significant $(p<0.05)$

\section{Discussion}

In this study we evaluated the role of CTC and DTC in colon cancer patients who were scheduled for potentially curative colon carcinoma resection. We show that CTC detection by CK20 RT-PCR is a highly sensitive and independent prognostic factor for OS and DFS in colon cancer patients.

In our study we applied two different technological approaches in parallel, i.e. RT-PCR and immunocytochemistry to detect CTC and DTC. Firstly, we employed a highly sensitive and specific nested CK20 RT-PCR to detect CTC and DTC. With this technique we were able to achieve detection rates of $37 \%$ in the blood and $35 \%$ in the BM. This technique is validly more sensitive than antibody-based detection of either intracellular protein markers (cytokeratins) or the cell surface EpCAM antigen, which yield detection rates of 22.3 and $19.7 \%$, respectively for DTC in the bone marrow. For colorectal cancer patients in particular average detection rates of only $10.5 \%$ for CTC with the CellSearch ${ }^{\mathrm{Tx}}$ system have been reported [19]. In addition to this, it has been demonstrated that the sensitivity of the qRT-PCR method is superior to immunomagnetic-based tools concerning detection of CTC in colorectal cancer patients [20].

Furthermore, we used immunocytochemistry to detect DTC with anti-pan-cytokeratin or anti-EpCAM antibodies. Using this methodological approach, we achieved detection rates of 22.3 and $19.7 \%$, respectively. Recent reports have shown, that additionally incorporating CK20 RT-PCR as a biomarker, the sensitivity of the CellSearch ${ }^{\mathrm{TM}}$ system could substantially be enhanced in colorectal cancer patients [21].

Though the major limitation of immunomagnetic enumeration platforms is, that only the subset of EpCAM+ CTC is detected. It has been shown, that a subgroup of
CTC may exist, that has undergone epithelial to mesenchymal transition (EMT) and does not express EpCAM [22, 23]. Moreover, the cells that have encountered EMT have undergone dedifferentiation, increased cell mobility and have lost cell adhesions. These attributes make this subset of cells even more likely to have an aggressive metastatic potential and high drug resistance [24, 25].

In our study, we were able to show that disseminated tumor cells in the bone marrow have a different impact on overall survival than circulating tumor cells in the blood. Despite the combined detection rate for DTC in nearly $50 \%$ of the patients with either CK20 RT-PCR or immunocytochemistry the prognostic significance of DTC in the bone marrow was negligible compared to CTC in the peripheral blood. In clinical practice BM metastases are rarely seen in colon cancer. Solely in more advanced tumor stages, but what is the biological role of DTC in the bone marrow? This implies, that this organ might have a high ability to clear disseminated colon cancer cells or to prevent their proliferation. During the last years these findings have led to a hypothesis of tumor cell dormancy and tumor stem cells that reside in the bone marrow niche and recirculate after years to form distant metastases [26-28]. Recently, we have been able to show that patients with colorectal liver metastases and detectable DTC in the bone marrow at the time of liver surgery, had an unfavorable prognosis after complete liver metastases resection [29]. Interestingly, in this series of patients with apparent macro-metastases in the liver, CTC in the blood were not an additional negative prognostic marker. These findings support the hypothesis, that detection of DTC in the BM per se is not a negative prognostic factor, but only if under certain circumstances these dormant tumor cells re-circulate and consequently form solid organ metastases.

We included in our study exclusively patients with colon cancer as we have previously reported that in rectal cancer DTC and CTC have no prognostic influence on OS [12]. In accordance to our findings several other groups have also described that in rectal cancer CTC are not a prognostic factor for OS [30-32]. There are several clinical and biological hallmarks indicating that colon and rectal cancer are different with respect to anatomy, function and embryological origin [33, 34]. Furthermore, the treatment of primary non-metastasized colon and rectal cancer is different [35]. Future studies evaluating the role of circulating tumor cells should at least provide subgroup analysis of rectal and colon cancer patients.

The detection of CTC correlates with a higher Tcategory and the existence of liver metastases. In addition, patients with detectable CTC have a significantly higher risk to develop a recurrent disease. Interestingly, the detection of CTC did not correlate with lymph node metastases, which is in line with previous 
reports $[19,36]$. Furthermore, in our study population we were not able to prove a prognostic influence of detectable CTC or DTC in early stage (UICC stage II) patients. As adjuvant therapy in patients without lymph node metastases remains a controversial issue, further molecular markers or risk factors are urgently needed to identify patients at risk for later metastases.

The biological significance of CTC or DTC is still uncertain. We and other groups can detect CTC in approx. $30 \%$ of T1-2 tumor patients $[19,37]$, but these patients have a very good prognosis. Recently, it has been shown with gene expression profiles of CTCs that there is a strong heterogeneity between the tumor cells. CTC are mostly dormant cells and disguised by the immune system, which may explain the low number of metastases opposing a high number of CTC in the blood flow [38]. It has been shown, that a subset of CTC express functional cancer stem cell characteristics [39]. Furthermore, in breast cancer a subset of metastases-initiating cells (MIC) among CTC was described that have a distinguished phenotype [40]. For the future, not the pure detection of DTC and CTC will be fundamental, but the quantification and phenotypic characterization of molecular markers of CTC that might allow selective targeting of the metastatic cascade of colon cancer.

\section{Conclusions}

In our study we were able to show that detection of CTC with CK20 RT-PCR is a highly specific and independent prognostic marker in colon cancer patients. Patients with CTC in the blood had a significantly higher risk to develop a tumor recurrence during the follow-up. In contrast to this, detection of DTC in the bone marrow with CK20 RT-PCR or immunohistochemistry with anti-EpCAM antibody is not associated with a negative prognostic influence.

\section{Additional file}

Additional file 1: Immunuohistochemistry staining of different bone marrow samples showing positive disseminated tumor cells from different

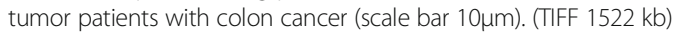

\section{Abbreviations}

BM: Bone marrow; Cl: Confidence interval; CK: Cytokeratin; CTC: Circulating tumor cells; DFS: Disease free survival; DTD: Disseminated tumor cells; EMT: Epithelial-mesenchymal transition; FAP: Familial adenomatosis polyposis; FDA: Food and Drug Administration; HR: Hazard ratio; MIC: Metastasesinitiating cell; OS: Overall survival; PCR: Polymerase chain reaction

\section{Acknowledgments}

The authors would like to thank Bianca Zinke and Liane Carstensen for outstanding technical assistance.

\section{Funding}

Deutsche Krebshilfe e.V., Bonn, Germany, and Johanna und Fritz Buch Gedächtnis-Stiftung, Hamburg, Germany. Samples were supplied by the Kiel CCC-biomaterial bank, funded by the BMBF (PopGen 2.0 Network/ P2N-01EY1103).

\section{Availability of data and materials}

The dataset (patient data set) will not be shared as it is part of a larger clinical dataset.

\section{Authors' contributions}

SH, HK and TB designed the study. SH analyzed the data and drafted the manuscript. CR and AW carried out the RT-PCR analysis. JT and CS designed the study and helped to draft the manuscript. AH and CS helped analyzing the data. All authors read and approved the final manuscript. AW conducted the immunohistochemistry analysis.

\section{Competing interests}

The authors declare that they have no competing interests.

\section{Consent for publication}

Not applicable.

\section{Ethics approval and consent to participate}

The study was approved by the local ethics committee of the Christian-Albrechts University, Kiel (A110/99) and all patients gave written informed consent prior to inclusion in the study.

\section{Author details}

${ }^{1}$ Department of General and Thoracic Surgery, University Hospital Schleswig-Holstein, Campus Kiel, Arnold-Heller Str. 7, 24105 Kiel, Germany. ${ }^{2}$ Division Molecular Oncology, Institute for Experimental Cancer Research, Cancer Center North, University Hospital Schleswig-Holstein, Campus Kiel, Arnold-Heller Str. 7, 24105 Kiel, Germany. ${ }^{3}$ Klinikum Osnabrück, Am Finkenhügel 1-3, 49076 Osnabrück, Germany.

Received: 21 June 2016 Accepted: 16 December 2016 Published online: 13 January 2017

\section{References}

1. Ries L, Melbert D, M. K, A. N, Miller B, Feuer E, Clegg L, Horner M, Howlader N, Eisner M et al: SEER Cancer Statistics Review, 1975-2004. In.: National Cancer Institute. Bethesda, MD; 2006.

2. Fidler IJ. The pathogenesis of cancer metastasis: the 'seed and soil' hypothesis revisited. Nat Rev Cancer. 2003;3(6):453-8.

3. Bilchik AJ, DiNome M, Saha S, Turner RR, Wiese D, McCarter M, Hoon DS, Morton DL. Prospective multicenter trial of staging adequacy in colon cancer: preliminary results. Arch Surg. 2006;141(6):527-33.

4. Burchill SA, Bradbury MF, Pittman K, Southgate J, Smith B, Selby P. Detection of epithelial cancer cells in peripheral blood by reverse transcriptase-polymerase chain reaction. Br J Cancer. 1995;71(2):278-81.

5. Mori M, Mimori K, Inoue H, Barnard GF, Tsuji K, Nanbara S, Ueo H, Akiyoshi $\mathrm{T}$. Detection of cancer micrometastases in lymph nodes by reverse transcriptase-polymerase chain reaction. Cancer Res. 1995;55(15):3417-20.

6. Zieglschmid V, Hollmann C, Bocher O. Detection of disseminated tumor cells in peripheral blood. Crit Rev Clin Lab Sci. 2005;42(2):155-96.

7. Salazar R, Roepman P, Capella G, Moreno V, Simon I, Dreezen C, LopezDoriga A, Santos C, Marijnen C, Westerga J, et al. Gene expression signature to improve prognosis prediction of stage II and III colorectal cancer. J Clin Oncol. 2011;29(1):17-24

8. Karapetis CS, Khambata-Ford S, Jonker DJ, O'Callaghan CJ, Tu D, Tebbutt NC, Simes RJ, Chalchal H, Shapiro JD, Robitaille S, et al. K-ras mutations and benefit from cetuximab in advanced colorectal cancer. N Engl J Med. 2008; 359(17):1757-65.

9. Moll R, Lowe A, Laufer J, Franke WW. Cytokeratin 20 in human carcinomas. A new histodiagnostic marker detected by monoclonal antibodies. Am J Pathol. 1992;140(2):427-47.

10. Soeth E, Roder C, Juhl H, Kruger U, Kremer B, Kalthoff $H$. The detection of disseminated tumor cells in bone marrow from colorectal-cancer patients by a cytokeratin-20-specific nested reverse-transcriptase-polymerase-chain reaction is related to the stage of disease. Int J Cancer. 1996;69(4):278-82.

11. Soeth E, Vogel I, Roder C, Juhl H, Marxsen J, Kruger U, Henne-Bruns D, Kremer $\mathrm{B}$, Kalthoff $\mathrm{H}$. Comparative analysis of bone marrow and venous blood isolates from gastrointestinal cancer patients for the detection of disseminated tumor cells using reverse transcription PCR. Cancer Res. 1997;57(15):3106-10. 
12. Hinz S, Roder C, Tepel J, Hendricks A, Schafmayer C, Becker T, Kalthoff H. Cytokeratin 20 positive circulating tumor cells are a marker for response after neoadjuvant chemoradiation but not for prognosis in patients with rectal cancer. BMC Cancer. 2015;15(1):953.

13. Lindemann F, Schlimok G, Dirschedl P, Witte J, Riethmuller G. Prognostic significance of micrometastatic tumour cells in bone marrow of colorectal cancer patients. Lancet. 1992;340(8821):685-9.

14. Bosch B, Guller U, Schnider A, Maurer R, Harder F, Metzger U, Marti WR. Perioperative detection of disseminated tumour cells is an independent prognostic factor in patients with colorectal cancer. Br J Surg. 2003;90(7):882-8

15. Koch M, Kienle P, Kastrati D, Antolovic D, Schmidt J, Herfarth C, von Knebel DM, Weitz J. Prognostic impact of hematogenous tumor cell dissemination in patients with stage II colorectal cancer. Int J Cancer. 2006;118(12):3072-7.

16. Cohen SJ, Punt CJ, lannotti N, Saidman BH, Sabbath KD, Gabrail NY, Picus J, Morse M, Mitchell E, Miller MC, et al. Relationship of circulating tumor cells to tumor response, progression-free survival, and overall survival in patients with metastatic colorectal cancer. J Clin Oncol. 2008;26(19):3213-21.

17. Gorges TM, Tinhofer I, Drosch M, Rose L, Zollner TM, Krahn T, von Ahsen O. Circulating tumour cells escape from EpCAM-based detection due to epithelial-to-mesenchymal transition. BMC Cancer. 2012;12:178.

18. Borgen E, Naume B, Nesland JM, Kvalheim G, Beiske K, Fodstad O, Diel I, Solomayer EF, Theocharous P, Coombes RC, et al. Standardization of the immunocytochemical detection of cancer cells in BM and blood: I. establishment of objective criteria for the evaluation of immunostained cells. Cytotherapy. 1999;1(5):377-88.

19. Bork U, Rahbari NN, Scholch S, Reissfelder C, Kahlert C, Buchler MW, Weitz J, Koch M. Circulating tumour cells and outcome in non-metastatic colorectal cancer: a prospective study. Br J Cancer. 2015;112(8):1306-13.

20. linuma H, Watanabe T, Mimori K, Adachi M, Hayashi N, Tamura J, Matsuda K, Fukushima R, Okinaga K, Sasako M, et al. Clinical significance of circulating tumor cells, including cancer stem-like cells, in peripheral blood for recurrence and prognosis in patients with Dukes' stage B and C colorectal cancer. J Clin Oncol. 2011;29(12):1547-55.

21. Welinder C, Jansson B, Lindell G, Wenner J. Cytokeratin 20 improves the detection of circulating tumor cells in patients with colorectal cancer. Cancer Lett. 2015:358(1):43-6.

22. Gradilone A, lacovelli R, Cortesi E, Raimondi C, Gianni W, Nicolazzo C, Petracca A, Palazzo A, Longo F, Frati L, et al. Circulating tumor cells and "suspicious objects" evaluated through Cell Search(R) in metastatic renal cell carcinoma. Anticancer Res. 2011;31(12):4219-21.

23. Raimondi C, Gradilone A, Naso G, Vincenzi B, Petracca A, Nicolazzo C, Palazzo A, Saltarelli R, Spremberg F, Cortesi E, et al. Epithelial-mesenchymal transition and stemness features in circulating tumor cells from breast cancer patients. Breast Cancer Res Treat. 2011;130(2):449-55.

24. Raimondi C, Gradilone A, Naso G, Cortesi E, Gazzaniga P. Clinical utility of circulating tumor cell counting through Cell Search((R)): the dilemma of a concept suspended in Limbo. OncoTargets Therapy. 2014;7:619-25.

25. Lim SH, Spring KJ, de Souza P, MacKenzie S, Bokey L. Circulating tumour cells and circulating nucleic acids as a measure of tumour dissemination in non-metastatic colorectal cancer surgery. Eur J Surg Oncol. 2015;41(3): 309-14.

26. Scholch S, Garcia SA, Iwata N, Niemietz T, Betzler AM, Nanduri LK, Bork U, Kahlert C, Thepkaysone ML, Swiersy A, et al. Circulating tumor cells exhibit stem cell characteristics in an orthotopic mouse model of colorectal cancer. Oncotarget. 2016;7(19):27232-42.

27. Wan L, Pantel K, Kang Y. Tumor metastasis: moving new biological insights into the clinic. Nat Med. 2013;19(11):1450-64.

28. Cavnar SP, Rickelmann AD, Meguiar KF, Xiao A, Dosch J, Leung BM, Cai Lesher-Perez S, Chitta S, Luker KE, Takayama S, et al. Modeling Selective Elimination of Quiescent Cancer Cells from Bone Marrow. Neoplasia (New York, NY). 2015;17(8):625-33.

29. Hinz S, Bockhorst J, Roder C, Egberts JH, Schafmayer C, Kuchler T, Becker T, Kalthoff $\mathrm{H}$. Disseminated tumor cells in the bone marrow negatively influence survival after resection of colorectal liver metastases. Ann Surg Oncol. 2012;19(8):2539-46.

30. Magni E, Botteri E, Ravenda PS, Cassatella MC, Bertani E, Chiappa A, Luca F, Zorzino L, Bianchi PP, Adamoli L, et al. Detection of circulating tumor cells in patients with locally advanced rectal cancer undergoing neoadjuvant therapy followed by curative surgery. Int J Colorectal Dis. 2014;29(9):1053-9.

31. Nesteruk D, Rutkowski A, Fabisiewicz S, Pawlak J, Siedlecki JA, Fabisiewicz A. Evaluation of prognostic significance of circulating tumor cells detection in rectal cancer patients treated with preoperative radiotherapy: prospectively collected material data. Biomed Res Int. 2014:2014:712827.

32. Zitt M, Zitt M, Muller HM, Dinnewitzer AJ, Schwendinger V, Goebel G, De Vries A, Amberger A, Weiss H, Margreiter R, et al. Disseminated tumor cells in peripheral blood: a novel marker for therapy response in locally advanced rectal cancer patients undergoing preoperative chemoradiation. Dis Colon Rectum. 2006;49(10):1484-91.

33. lacopetta B. Are there two sides to colorectal cancer? Int J Cancer. 2002;101(5):403-8.

34. Li FY, Lai MD. Colorectal cancer, one entity or three. J Zhejiang Univ Sci B. 2009:10(3):219-29.

35. Tamas K, Walenkamp AM, de Vries EG, van Vugt MA, Beets-Tan RG, van Etten B, de Groot DJ, Hospers GA. Rectal and colon cancer: Not just a different anatomic site. Cancer Treat Rev. 2015;41(8):671-9.

36. Sotelo MJ, Sastre J, Maestro ML, Veganzones S, Vieitez JM, Alonso V, Gravalos C, Escudero P, Vera R, Aranda E, et al. Role of circulating tumor cells as prognostic marker in resected stage III colorectal cancer. Ann Oncol. 2015;26(3):535-41.

37. Flatmark K, Borgen E, Nesland JM, Rasmussen H, Johannessen HO, Bukholm I, Rosales R, Harklau L, Jacobsen HJ, Sandstad B, et al. Disseminated tumour cells as a prognostic biomarker in colorectal cancer. Br J Cancer. 2011;104(9):1434-9.

38. Steinert G, Scholch S, Niemietz T, Iwata N, Garcia SA, Behrens B, Voigt A Kloor M, Benner A, Bork U, et al. Immune escape and survival mechanisms in circulating tumor cells of colorectal cancer. Cancer Res. 2014;74(6):1694-704.

39. Grillet F, Bayet E, Villeronce O, Zappia L, Lagerqvist EL, Lunke S, CharafeJauffret E, Pham K, Molck C, Rolland N et al: Circulating tumour cells from patients with colorectal cancer have cancer stem cell hallmarks in ex vivo culture. Gut 2016. (Epub ahead of print).

40. Baccelli I, Schneeweiss A, Riethdorf S, Stenzinger A, Schillert A, Vogel V, Klein C, Saini M, Bauerle T, Wallwiener M, et al. Identification of a population of blood circulating tumor cells from breast cancer patients that initiates metastasis in a xenograft assay. Nat Biotechnol. 2013;31(6): 539-44.

\section{Submit your next manuscript to BioMed Central and we will help you at every step:}

- We accept pre-submission inquiries

- Our selector tool helps you to find the most relevant journal

- We provide round the clock customer support

- Convenient online submission

- Thorough peer review

- Inclusion in PubMed and all major indexing services

- Maximum visibility for your research

Submit your manuscript at www.biomedcentral.com/submit 